OPEN ACCESS

Edited by:

Wenbo Wang

Lanzhou Institute of Chemical Physics

(CAS), China

Reviewed by:

Jinxing Ma,

University of New South Wales,

Australia

Fenghua Liu,

Ningbo Institute of Industrial Technology (CAS), China

*Correspondence: Xiazhang L xiazhang@cczu.edu.cn

Chao Yao

yaochao@cczu.edu.cn

Specialty section:

This article was submitted to Green and Sustainable Chemistry, a section of the journal Frontiers in Chemistry

Received: 25 June 2018 Accepted: 20 September 2018 Published: 05 October 2018

Citation:

Wu F, Li X, Zhang H, Zuo S and Yao C (2018) Z-Scheme Photocatalyst Constructed by Natural Attapulgite and Upconversion Rare Earth Materials for Desulfurization.

Front. Chem. 6:477.

doi: 10.3389/fchem.2018.00477

\section{Z-Scheme Photocatalyst Constructed by Natural Attapulgite and Upconversion Rare Earth Materials for Desulfurization}

\author{
Fengqin Wu, Xiazhang Li*, Haiguang Zhang, Shixiang Zuo and Chao Yao* \\ Advanced Catalysis and Green Manufacturing Collaborative Innovation Center, Changzhou University, Changzhou, China
}

The $\mathrm{Er}^{3+}: \mathrm{CeO}_{2} / \mathrm{ATP}$ (attapulgite) nanocomposites were prepared by a facile precipitation method. The samples were characterized by various measurements. XRD and TEM showed that $\mathrm{Er}^{3+}: \mathrm{CeO}_{2}$ nanoparticles were well-crystallized and loaded on the surface of ATP. The visible light was converted into ultraviolet light by $\mathrm{Er}^{3+}: \mathrm{CeO}_{2}$ as evidenced by upconversion photoluminance (PL) analysis. The mass ratio of $\mathrm{Er}^{3+}: \mathrm{CeO}_{2}$ to ATP on the desulfurization efficiency was investigated. Results showed that the desulfurization rate reached $87 \%$ under $4 \mathrm{~h}$ visible light irradiation when the mass ratio was 4:10. The mechanism was put forward as follows. $\mathrm{Er}^{3+}: \mathrm{CeO}_{2}$ and ATP formed Z-scheme heterostructure intermediated by oxygen vacancy, leading to the enhanced separation of photogenerated charges and preservation of high oxidation-reduction potential, both of which favored for the generation of radicals to oxidize sulfur species.

Keywords: attapulgite, upconversion, rare earth, Z scheme, photocatalyst

\section{INTRODUCTION}

Massive use of fuel has given rise to serious environmental problem including acid rain and atmospheric haze, since the combustion of sulfur compounds in fuels leads to the emission of pernicious $\mathrm{SO}_{\mathrm{x}}$. Therefore, it is imperative to develop new desulfurization technology to satisfy fuel purification (Liu et al., 2017; Zhang et al., 2018). The conventional hydrodesulfurization (HDS) has been extensively used in removing sulfur compound in fuel, which requires high temperature, pressure and expensive hydrogen (Wang et al., 2016; Zeng et al., 2017). Owing to the drawbacks of HDS for removing sulfur compound, many alternative strategies have been developed, including extractive desulfurization (Raj et al., 2017), oxidative desulfurization (Khodadadi Dizaji et al., 2018), biodesulfurization (Agarwal et al., 2016) and adsorption desulfurization (Yang et al., 2018). Among these strategies, oxidative desulfurization is considered as one of the promising strategy for deep desulfurization due to its cheap and efficient features. Particularly, photocatalytic oxidative desulfurization is deemed as a potential candidate. In our previous work, we have prepared attapulgite- $\mathrm{CeO}_{2} / \mathrm{MoS}_{2}, \mathrm{CeO}_{2}$ /attapulgite/g- $\mathrm{C}_{3} \mathrm{~N}_{4}$ and $\mathrm{BiP}_{1-\mathrm{x}} \mathrm{V}_{\mathrm{x}} \mathrm{O}_{4}$ /attapulgite nanocomposites and found that the photocatalytic oxidative desulfurization rate reached as high as more than 90\% under the irradiation of visible light (Li et al., 2016, 2017, 2018). As a natural clay material, attapulgite (ATP) has large specific surface area, superior adsorption performance and unique pore structure, which is widely used in catalyst support (Zhang et al., 2016b). Interestingly, the incorporation of $\mathrm{Fe}_{2} \mathrm{O}_{3}$ endows ATP with semiconductor property to some extent. Zhang et al. (Zhang et al., 2013, 2016a) sensitized ATP by taking advantage of eosine Y and CdS to generate 
hydrogen from water. Li et al. (Ma et al., 2018) prepared CQDs/ATP nanocomposites with visible light response. However, ATP can only be stimulated by ultraviolet light which is accounted for $5 \%$ in solar light due to its wide band gap (Balaji et al., 2017).

The upconversion luminescence materials have attracted great attentions since they can absorb and upconvert long wave light with low-energy to short wave light with high-energy (Feng et al., 2013). In the general composition of upconversion luminescence material, the rare earth element has a rich $4 \mathrm{f}$ energy level enabling the electrons jump easily from high to low energy level. Among the rare earth family, $\mathrm{Er}^{3+}$ has abundant energy levels and higher upconversion luminescence efficiency, making it as a excellent candidate for the conversion from visible to UV light (Pickering et al., 2017). The $\mathrm{Er}^{3+}$ can be easily doped into the crystal lattice of $\mathrm{CeO}_{2}$ along with the production of oxygen vacancy since the ion radius of $\mathrm{Ce}^{4+}$ is very close to $\mathrm{Er}^{3+}$ (Wu et al., 2014). Meanwhile, $\mathrm{CeO}_{2}$ has high chemical stability and low phonon energy, making it suitable as matrix materials in upconversion. Han et al prepared upconversion Er, $\mathrm{Yb}-\mathrm{CeO}_{2}$ hollow spheres for improving the efficiency of dyesensitized solar cells (Han et al., 2017). However, rare report has been put on the heterostructure constructed by rare earth doped upconversion luminescence materials (Bhethanabotla et al., 2016). Moreover, the decline of oxidation-reduction ability in traditional type heterostructure is non-negligible. It is worth noting that Z-type heterostructure causes the annihilation of photo-generated charges with lower reduction and oxidation potential, therefore leading to the preservation of high redox potential for the heterostructure (Šutka et al., 2018). Intriguingly, the self-generated oxygen vacancy has been proposed as mediator in the indirect Z-scheme with the absence of noble metals, such as $\mathrm{Au}, \mathrm{Ag}$, etc. For instance, Ding et al. (Ding et al., 2016) prepared $\mathrm{BiO}_{1-\mathrm{x}} \mathrm{Br} / \mathrm{Bi}_{2} \mathrm{O}_{2} \mathrm{CO}_{3}$ in which the oxygen vacancy of $\mathrm{BiO}_{1-\mathrm{x}} \mathrm{Br}$ acted as the medium of transmission for electrons and the recombination center of photogenerated electrons and holes.

In this work, the Er doped $\mathrm{CeO}_{2}$ upconversion luminescence oxide was immobilized on ATP. The doping fraction of $\mathrm{Er}^{3+}$ was adjusted to achieve the strongest emission of ultraviolet light to stimulate ATP. Meanwhile, $\mathrm{CeO}_{2}$ : Er and ATP formed Z-type heterostructure intermediated by oxygen vacancy, which effectively preserved redox potential so as to improve the photocatalytic desulfurization activity of $\mathrm{Er}^{3+}: \mathrm{CeO}_{2} / \mathrm{ATP}$.

\section{EXPERIMENTAL SECTION}

\section{Materials}

ATP powders were obtained from Xuyi, China. $\mathrm{Ce}\left(\mathrm{NO}_{3}\right)_{3} \cdot 6 \mathrm{H}_{2} \mathrm{O}$, $\operatorname{Er}\left(\mathrm{NO}_{3}\right)_{3} \cdot 5 \mathrm{H}_{2} \mathrm{O}$, hexamine $\left(\mathrm{C}_{2} \mathrm{H}_{12} \mathrm{~N}_{4}, \mathrm{HMT}\right)$, octane $\left(\mathrm{C}_{8} \mathrm{H}_{18}\right)$, dibenzothiophene $\left(\mathrm{C}_{12} \mathrm{H}_{8} \mathrm{~S}\right)$ and acetonitrile $\left(\mathrm{C}_{2} \mathrm{H}_{3} \mathrm{~N}\right)$ were purchased from Sionpharm Chemical Reagent Co., Ltd. All reagents were analytical grade without further purification.

\section{Synthesis of $\mathrm{Er}^{3+}: \mathrm{CeO}_{2} / \mathrm{ATP}$}

$\mathrm{Er}^{3+}: \mathrm{CeO}_{2} /$ ATP composites were synthesized via a onestep precipitation method. Typically, adequate amount of $\mathrm{Ce}\left(\mathrm{NO}_{3}\right)_{3} \cdot 6 \mathrm{H}_{2} \mathrm{O}, \mathrm{Er}\left(\mathrm{NO}_{3}\right)_{3} \cdot 5 \mathrm{H}_{2} \mathrm{O}$ and $1 \mathrm{~g}$ ATP were dissolved in
$100 \mathrm{~mL}$ deionized water and mixed together, followed by adding excess HMT (molar ratio of HMT to $\mathrm{Ce}\left(\mathrm{NO}_{3}\right)_{3}$ was $5: 1$ ). The molar fraction of $\mathrm{Er}(\mathrm{Er} / \mathrm{Ce}+\mathrm{Er})$ was adjusted from 0.5 to $2.5 \%$, and the mass ratio of $\mathrm{Er}^{3+}: \mathrm{CeO}_{2}$ to ATP was adjusted from 1:10 to $5: 10$. Then the mixture was heated in a water bath at $80^{\circ} \mathrm{C}$ for $2 \mathrm{~h}$. After cooled down to room temperature, the precipitate was washed with deionized water for three times. Subsequently, the obtained solid was dried in vacuum at $80^{\circ} \mathrm{C}$ for $10 \mathrm{~h}$, and finally calcined at $300^{\circ} \mathrm{C}$ for $2 \mathrm{~h}$.

\section{Materials Characterization}

The powder X-ray diffraction (XRD) was performed with a $\mathrm{D} / \mathrm{max}$ 2500PC diffractometer equipped with a $\mathrm{Cu}-\mathrm{K} \alpha$ radiation $\left(\lambda=1.5406 \AA\right.$ ) at a scanning speed of $6^{\circ} \mathrm{min}^{-1}$ from 5 to $80^{\circ}$. The morphology was investigated with a JEM-2100 transmission election microscope (TEM) operating at $200 \mathrm{kV}$. Raman spectra were collected with a Renishaw (UK) spectrometer with an Ar ion laser of $514 \mathrm{~nm}$ excitation. The ultraviolet visible (UVVis) spectra were acquired using a UV-2500 Shimadzu UV-Vis spectrophotometer. The photoluminescence (PL) spectra were collected with the PerkinElmer LS45 at room temperature. The $\mathrm{X}$-ray photoelectron spectroscopy (XPS) was performed with a PHI 5300 equipped with $\mathrm{K} \alpha$ in the condition of $284.6 \mathrm{eV}$ for $\mathrm{C} 1 \mathrm{~s}$.

\section{Photocatalytic Oxidative Desulfurization}

The photocatalytic desulfurization performance of $\mathrm{Er}^{3+}: \mathrm{CeO}_{2} / \mathrm{ATP}$ was carried out by degradating the model gasoline using a photocatalytic reaction apparatus (GHX-2) which was equipped with a $300 \mathrm{~W}$ xenon lamp. $0.4 \mathrm{~g}$ DBT was dissolved into $500 \mathrm{~mL}$ octane to acquire the model gasoline with sulfur compounds of $200 \mathrm{ppm}$. Then the model gasoline and catalysts were added into the photocatalytic reactor and kept 30 min with magnetic stirring to ensure adsorption equilibrium. Subsequently, simulated solar light using UV-cut off was irradiated during the reaction with the irradiation intensity of $30 \mathrm{~W} / \mathrm{cm}^{2}$. The samples were collected twice an hour to satisfy the extraction process. The rest of sulfur content was measured by a sulfur determination device (THA2000S), and the desulfurization rate $\mathrm{D}$ was calculated based on the following formula:

$$
\mathrm{D}=\left(1-\frac{C}{C_{0}}\right) \times 100 \%
$$

where $\mathrm{C}_{0}$ is the initial sulfur content of the model gasoline and $\mathrm{C}$ is the final sulfur content.

\section{RESULTS AND DISCUSSIONS}

\section{XRD Analysis}

Figure 1 shows the XRD patterns of ATP, $\mathrm{CeO}_{2} / \mathrm{ATP}$ and $\mathrm{Er}^{3+}: \mathrm{CeO}_{2} / \mathrm{ATP}$. In Figure $\mathbf{1 A}$ the characteristic peaks at 8.21, 19.75 , and $26.54^{\circ}$ Correspond to the (110), (040), and (400) plane of pure ATP (Zhao et al., 2016). The characteristics at 28.55, $33.07,47.48$, and $56.34^{\circ}$ Correspond to the (111), (200), (220), and (311) plane of $\mathrm{CeO}_{2}$ (JCPDS 43-1002). However, there is no characteristic peak of $\mathrm{Er}$ in $\mathrm{Er}^{3+}: \mathrm{CeO}_{2} / \mathrm{ATP}$ composites, which 

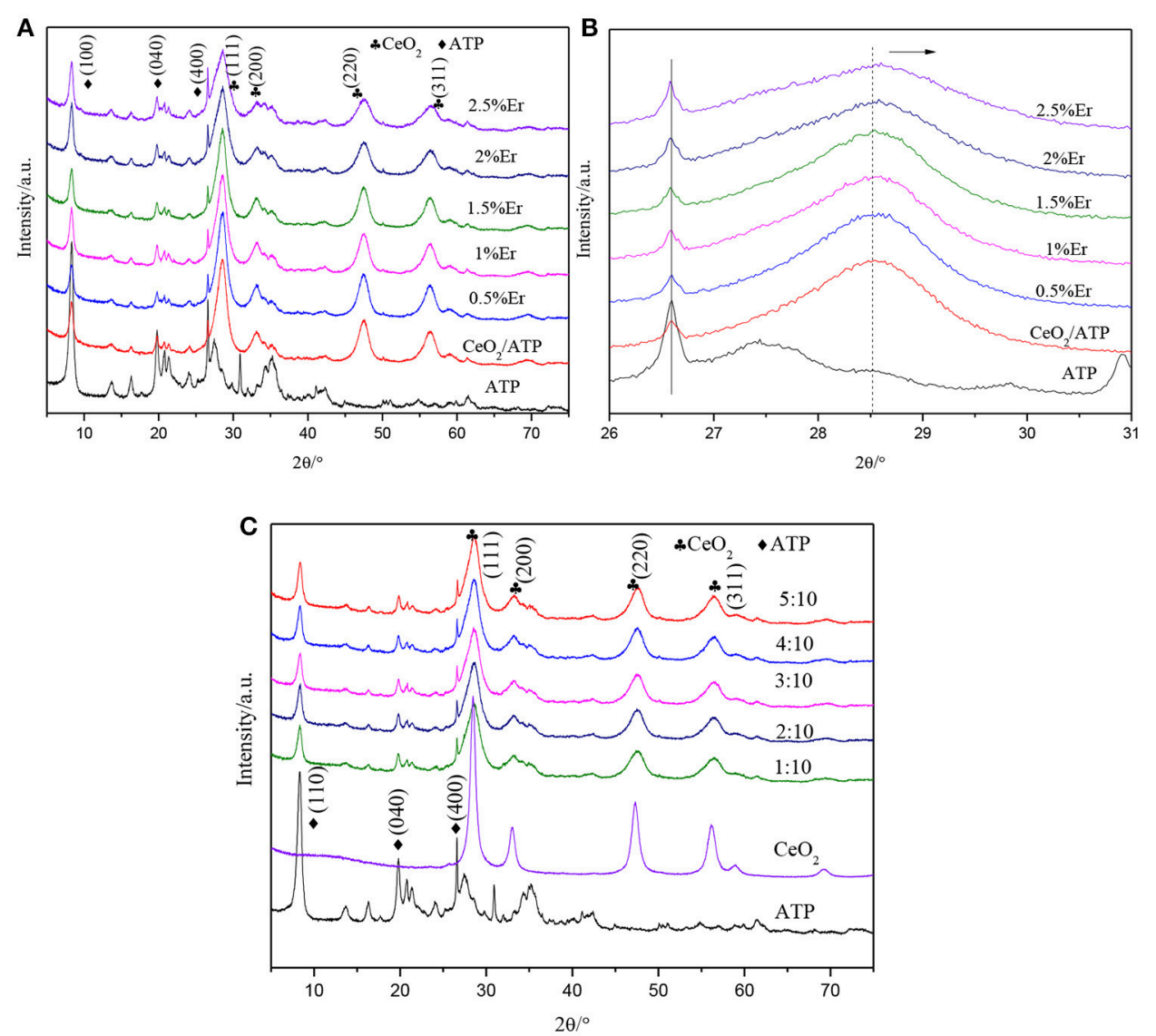

FIGURE 1 | XRD patterns of ATP, $\mathrm{CeO}_{2} / \mathrm{ATP}$ and $\mathrm{Er}^{3+}: \mathrm{CeO}_{2} / \mathrm{ATP}$ with various molar fractions of $\mathrm{Er}$ doping (A), the enlarged diffraction peak from 26 to $31^{\circ}$ (B), and different mass ratio of $\mathrm{Er}^{3+}: \mathrm{CeO}_{2}$ to ATP (C).

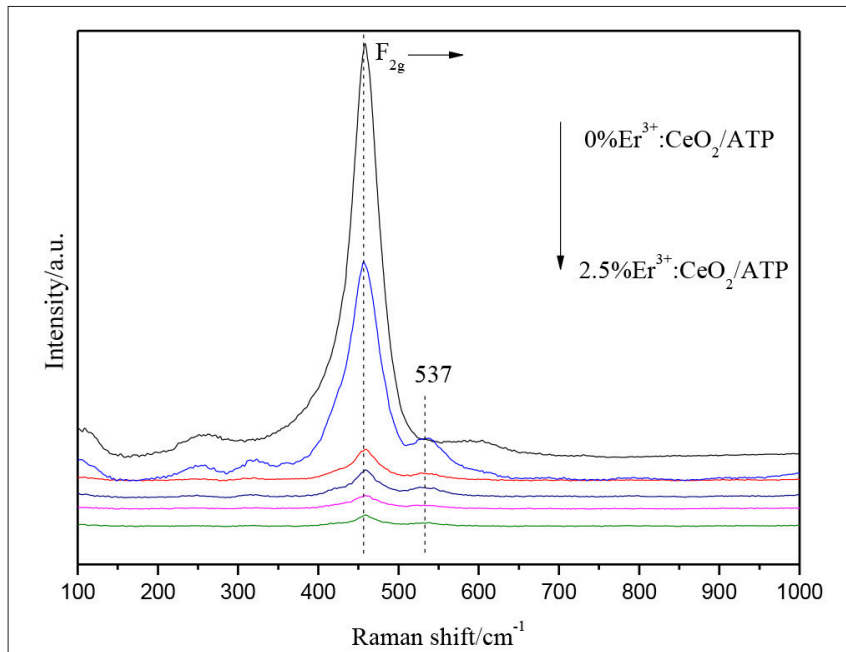

FIGURE 2 | Raman patterns of $\mathrm{CeO}_{2} /$ ATP and $\mathrm{Er}^{3+}: \mathrm{CeO}_{2} /$ ATP.

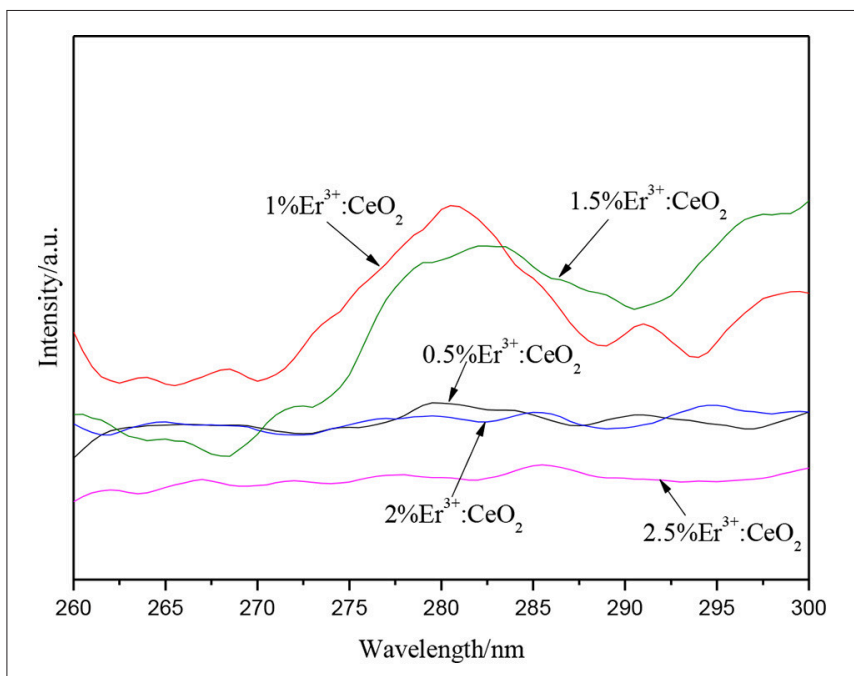

FIGURE 3 | Upconversion PL patterns of different Er doping fraction. may be due to the small doping amount of Er. In Figure 1B, the characteristic peak at $28.55^{\circ}$ shows slight shift to higher Bragg angle, implying that the $\mathrm{Er}^{3+}$ dopant results in the lattice contraction due to the fact that $\operatorname{Er}^{3+}(0.88 \AA)$ replaced the $\mathrm{Ce}^{4+}(0.92 \AA)$, subsequently leading to the lattice distortion and formation of oxygen vacancies (Li et al., 2012). Figure 1C shows 

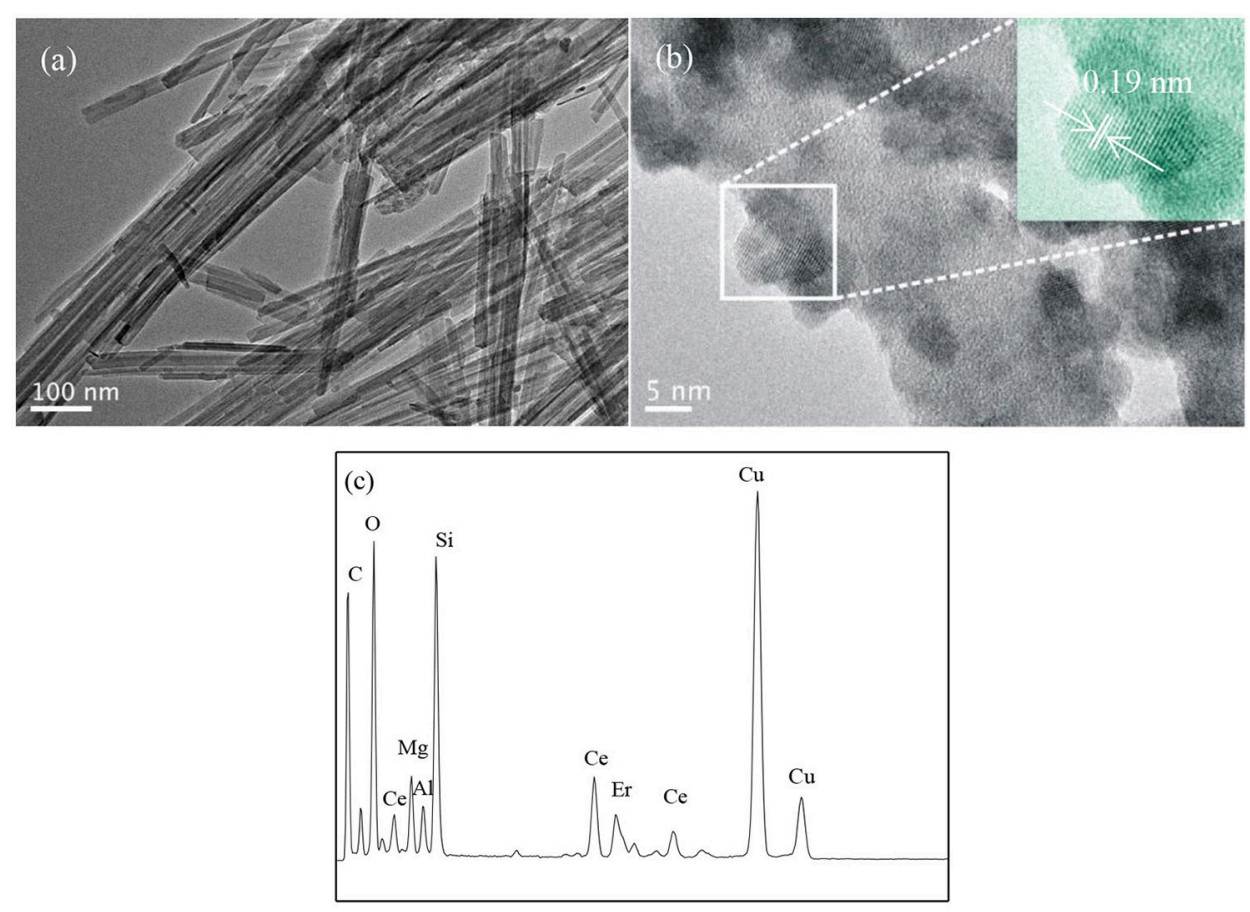

$\mathrm{E} / \mathrm{keV}$

FIGURE 4 | TEM images of ATP (a), $\mathrm{Er}^{3+}: \mathrm{CeO}_{2} / \mathrm{ATP}$ (b), and EDS of $\mathrm{Er}^{3+}: \mathrm{CeO}_{2} / \mathrm{ATP}$ (c).
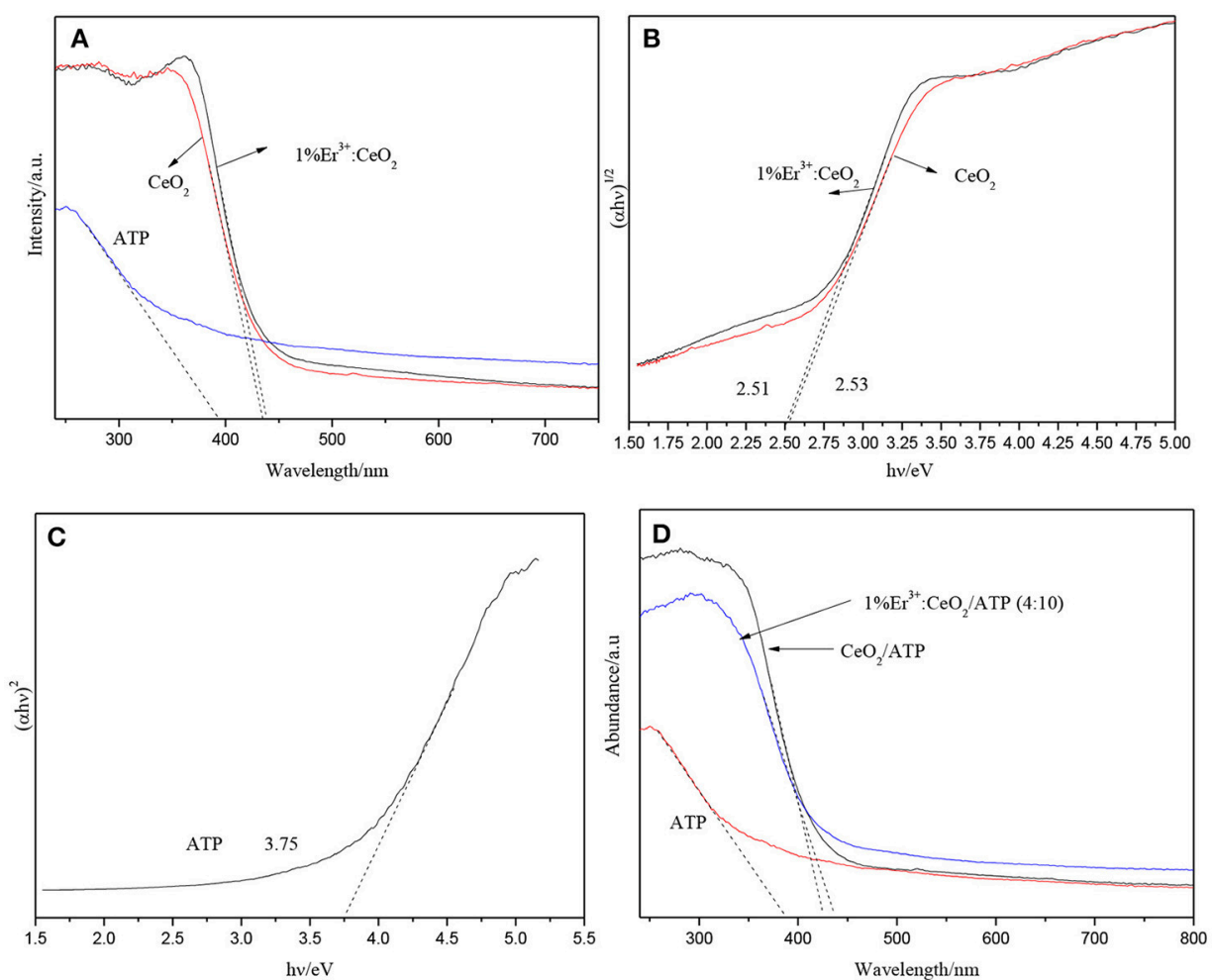

FIGURE 5 | UV-Vis patterns of ATP, $\mathrm{CeO}_{2}$, and $1 \% \mathrm{Er}^{3+}: \mathrm{CeO}_{2}$ (A), the plots of transformed Kubelka-Munk function vs. light energy of $\mathrm{CeO}_{2}$, and $1 \% \mathrm{Er}^{3+}: \mathrm{CeO}_{2}$ (B), the plots of transformed Kubelka-Munk function vs. light energy of ATP (C), and the UV-Vis patterns of ATP, $\mathrm{CeO}_{2}$, and $1 \% \mathrm{Er}^{3+}: \mathrm{CeO}_{2}(4: 10)(\mathbf{D})$. 
the XRD patterns of different mass ratio of $\mathrm{Er}^{3+}: \mathrm{CeO}_{2}$ to ATP. With the increase of mass ratio, the characteristic peak intensity of ATP is gradually weakened whereas the intensity of $\mathrm{CeO}_{2}$ is

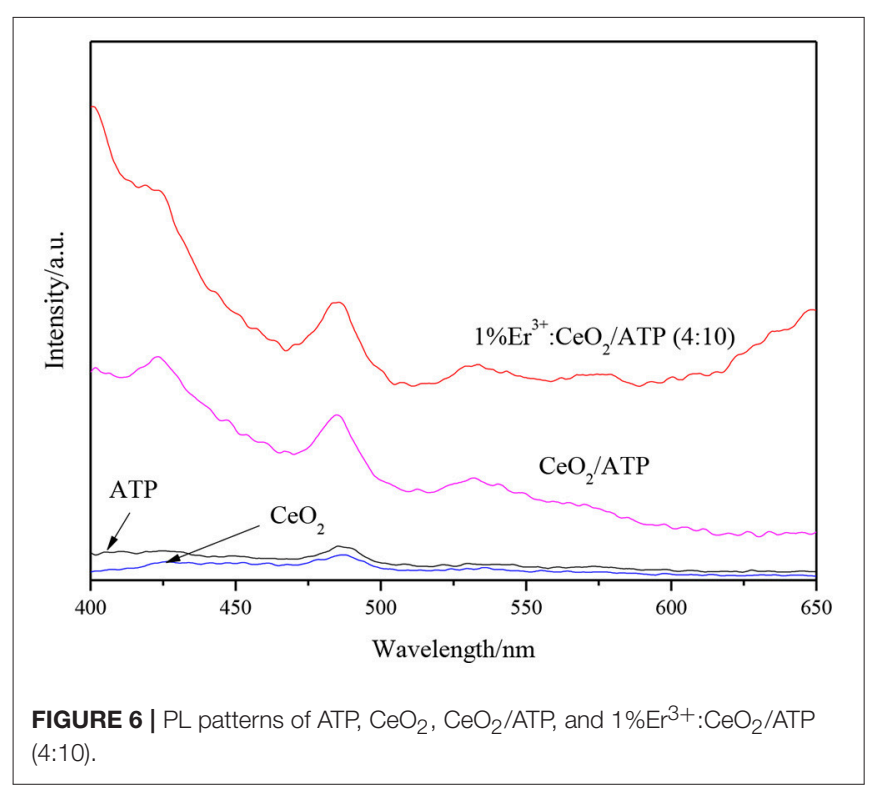

strengthened without any change of peak position, suggesting the immobilization of $\mathrm{Er}^{3+}: \mathrm{CeO}_{2}$ on ATP.

\section{Raman Analysis}

Figure 2 shows the Raman patterns of $\mathrm{CeO}_{2} / \mathrm{ATP}$ and $\mathrm{Er}^{3+}: \mathrm{CeO}_{2} / \mathrm{ATP}$. The peaks appearing in $454-459 \mathrm{~cm}^{-1}$ represent the $\mathrm{F}_{2 \mathrm{~g}}$ vibration mode for cubic $\mathrm{CeO}_{2}$ (Kumar and Kumar, 2017). Meanwhile, the peak intensity of $F_{2 g}$ is gradually decreased and the peak position is shifted to high wavenumber with the increase of Er, implying that $\mathrm{Er}$ is doped into $\mathrm{CeO}_{2}$ lattice. The peaks located at $537 \mathrm{~cm}^{-1}$ can be attributed to the formation of oxygen vacancies (Mamontov et al., 2016), due to the fact that $\mathrm{Er}^{3+}$ replaces $\mathrm{Ce}^{4+}$ resulting in the transformation from $\mathrm{Ce}^{4+}$ to $\mathrm{Ce}^{3+}$, subsequently oxygen vacancies are produced which is consistent with the results of XRD.

\section{Optical Analysis}

Figure 3 demonstrates the upconversion PL spectra of $\mathrm{Er}^{3+}: \mathrm{CeO}_{2}$ with different Er molar fraction. The upconversion luminescence was tested by the visible light of $488 \mathrm{~nm}$ as excitation light, while ultraviolet light was emitted near $281 \mathrm{~nm}$, corresponding to the energy transfer from the $2 \mathrm{D}_{5 / 2}$ excited state to the $4 \mathrm{I}_{15 / 2}$ ground state. The upconversion luminescence intensity of $\mathrm{Er}^{3+}: \mathrm{CeO}_{2}$ is gradually increased below $1 \%$, which
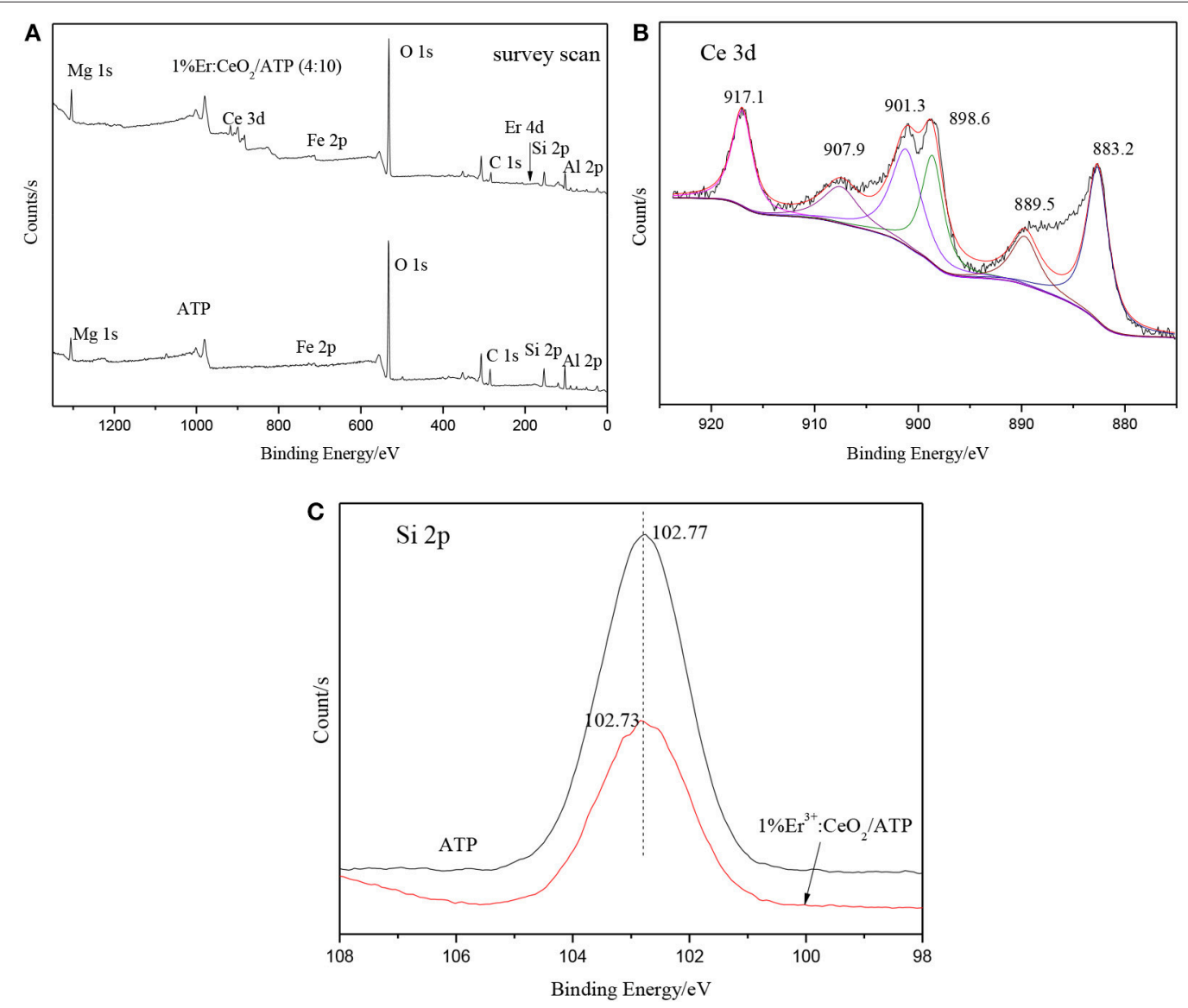

FIGURE 7 | XPS patterns of ATP, and $1 \% \mathrm{Er}^{3+}: \mathrm{CeO}_{2} / \mathrm{ATP}(4: 10)$, (A) Survey scan, (B) Ce 3d, and (C) Si 2p. 


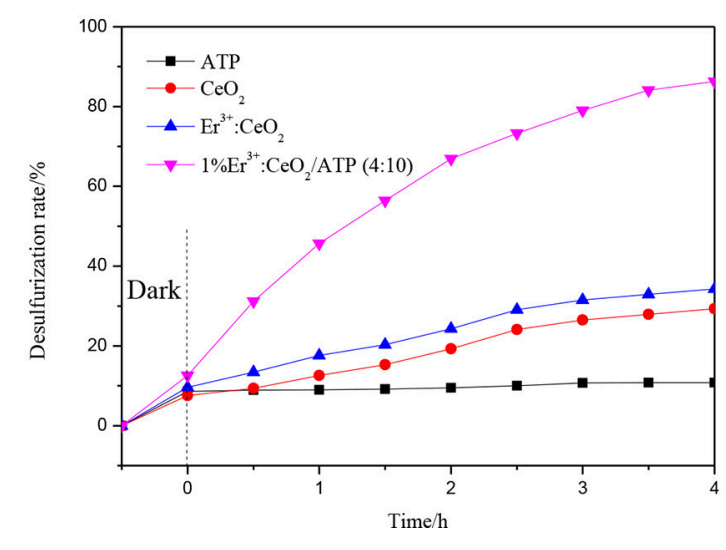

FIGURE 8 | Photocatalytic oxidation desulfurization efficiency with various catalysts.

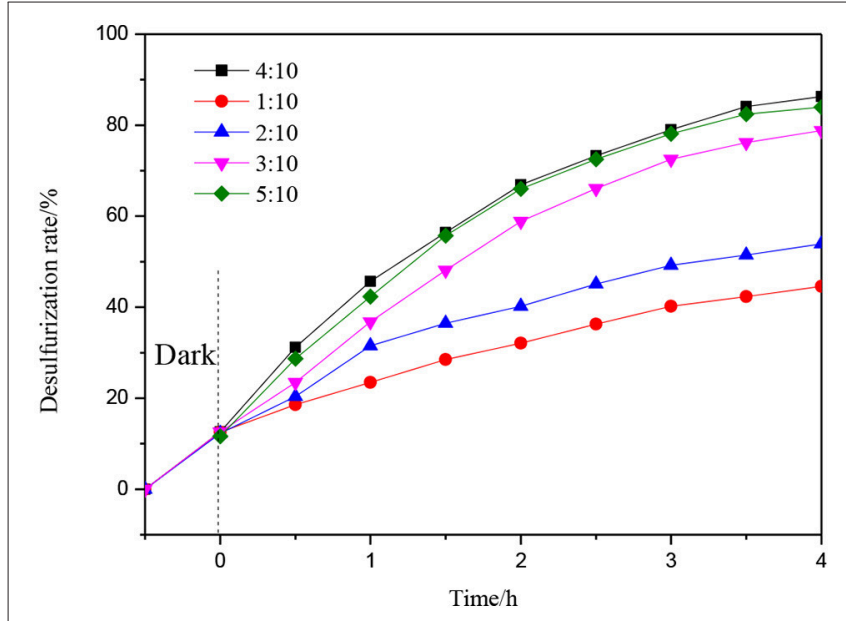

FIGURE 9 | Photocatalytic desulfurization efficiency with different mass ratio of $1 \% \mathrm{Er}^{3+}: \mathrm{CeO}_{2}$, and ATP.

reach strongest when the doping fraction is $1 \%$. Afterwards, the upconversion luminescence intensity is obviously decreased when doping fraction is more than $1 \%$ due to the fact that the excessive doping of $\mathrm{Er}^{3+}$ shortens the distance and enhances the interaction among $\mathrm{Er}^{3+}$ ions, leading to the concentration quenching of the upconversion luminescence (Ramasamy et al., 2013). Therefore, the upconversion luminescence intensity is gradually decreased, and the doping fraction is optimized to be $1 \%$.

\section{TEM Analysis}

Figure 4 shows the TEM results of ATP and $\mathrm{Er}^{3+}: \mathrm{CeO}_{2} / \mathrm{ATP}$. Figure 4a shows the pure ATP with a rod like structure having average diameter of $20-30 \mathrm{~nm}$. Figure $\mathbf{4 b}$ shows the HRTEM image of $1 \% \mathrm{Er}^{3+}: \mathrm{CeO}_{2} / \mathrm{ATP}(4: 10)$, and apparent nanoparticles are loaded on the surface of ATP. The inset lattice distance of $\mathrm{CeO}_{2}$ is $0.19 \mathrm{~nm}$ corresponding to the (220) plane of $\mathrm{CeO}_{2}$. Energy-dispersive spectroscopy (EDS) in Figure 4c displays Ce,
$\mathrm{Er}, \mathrm{Si}, \mathrm{Fe}, \mathrm{Mg}$, and $\mathrm{Al}$ elements, in which $\mathrm{Si}, \mathrm{Fe}, \mathrm{Mg}$ and $\mathrm{Al}$ are derived from ATP.

\section{UV-Vis Analysis}

Figure 5A shows the UV-Vis image of $\mathrm{CeO}_{2}, \mathrm{ATP}$, and Er doping fraction for $1 \% . \mathrm{CeO}_{2}$ has a certain response to visible light, while the absorption edge of $\mathrm{CeO}_{2}$ appears slightly red shift after doping of Er, which due to the fact that Er doping may change the band gap of the $\mathrm{CeO}_{2}$. Figure 5B shows the plots of transformed Kubelka-Munk function vs. light energy of $\mathrm{CeO}_{2}$ and $1 \% \mathrm{Er}^{3+}: \mathrm{CeO}_{2}$. The band gap of $\mathrm{CeO}_{2}$ and $1 \% \mathrm{Er}^{3+}: \mathrm{CeO}_{2}$ is estimated to be 2.53 and $2.51 \mathrm{eV}$, respectively. As shown in Figure $5 \mathrm{C}$, the band gap of ATP is estimated to be $3.75 \mathrm{eV}$, indicating ATP has ultraviolet response ability. It is reported that a semiconductor absorbs energy which is equal or larger than its band gap to produce photogenerated $\mathrm{e}^{-}$and $\mathrm{h}^{+}$(Zhuo et al., 2012). According to the results in Figure 3, the upconversion wavelength of $1 \% \mathrm{Er}^{3+}: \mathrm{CeO}_{2}$ locates at $281 \mathrm{~nm}$ corresponding to the band gap of $4.41 \mathrm{eV}$ larger than the band gap of ATP with $3.75 \mathrm{eV}$. Therefore, ATP can be excited by the upconversion emission of $1 \% \mathrm{Er}^{3+}: \mathrm{CeO}_{2}$. Figure 5D shows the UV-Vis pattern of ATP, $\mathrm{CeO}_{2} / \mathrm{ATP}$ and $1 \% \mathrm{Er}^{3+}: \mathrm{CeO}_{2} / \mathrm{ATP}$. Compared with ATP, the absorption edge of $\mathrm{CeO}_{2} /$ ATP and $1 \% \mathrm{Er}^{3+}: \mathrm{CeO}_{2} /$ ATP shows obviously red shift, which may favor for the photocatalytic performance.

\section{PL Analysis}

In order to investigate the recombination effect of photogenerated electrons and holes, PL analysis is performed under excitation of $300 \mathrm{~nm}$. Figure 6 shows the PL patterns of ATP, $\mathrm{CeO}_{2}, \mathrm{CeO}_{2} / \mathrm{ATP}$ and $1 \% \mathrm{Er}^{3+}: \mathrm{CeO}_{2} / \mathrm{ATP}$ (4:10). The emission peak of ATP is displayed, indicating that the photogenerated electrons and holes were recombined due to the fact that few $\mathrm{Fe}_{2} \mathrm{O}_{3}$ is stimulated to produce the photogenerated electrons and holes. Compared with pure ATP and $\mathrm{CeO}_{2}$, the intensity of the emission peak of $\mathrm{CeO}_{2} / \mathrm{ATP}$ and $1 \% \mathrm{Er}^{3+}: \mathrm{CeO}_{2} / \mathrm{ATP}(4: 10)$ is significantly increased. In general, the intensity of the emission peak of PL is inversely proportional to the separation efficiency of the photogenerated charges. Obviously, the phenomenon described in the Figure 6 violates the traditional law, which may be due to the unique Z-type heterostructure formed by $\mathrm{Er}^{3+}: \mathrm{CeO}_{2}$ and ATP.

\section{XPS Analysis}

Figure 7 shows the XPS patterns of ATP and $1 \% \mathrm{Er}^{3+}: \mathrm{CeO}_{2} / \mathrm{ATP}$ (4:10). Figure 7A is the survey scan indicating the existence of $\mathrm{Mg}, \mathrm{Fe}, \mathrm{Si}, \mathrm{Al}, \mathrm{Ce}, \mathrm{Er}$, and $\mathrm{C}$ elements where $\mathrm{Mg}, \mathrm{Fe}, \mathrm{Si}$, and $\mathrm{Al}$ are originated from ATP, Ce and Er are originated from $\mathrm{Er}^{3+}: \mathrm{CeO}_{2}$. As shown in Figure 7B, the characteristic peaks of 883.2, 898.6, and $907.9 \mathrm{eV}$ are ascribed to $\mathrm{Ce}^{3+}$ while the characteristic peaks of $889.5,901.3$, and $917.1 \mathrm{eV}$ are ascribed to $\mathrm{Ce}^{4+}$, which is close to our previous result with respect to $\mathrm{Ce} 3 \mathrm{~d}$ in $\mathrm{CeO}_{2} / \mathrm{ATP}$, ( $\mathrm{Li}$ et al., 2017) indicating that the surface of $\mathrm{CeO}_{2}$ contains oxygen vacancy. (Peng et al., 2017) The characteristic peak position of Si $2 \mathrm{p}$ in $1 \% \mathrm{Er}^{3+}: \mathrm{CeO}_{2} / \mathrm{ATP}(4: 10)$ is lower than that of ATP shown in Figure 7C, due to the fact that the Si-O-Si bond may 

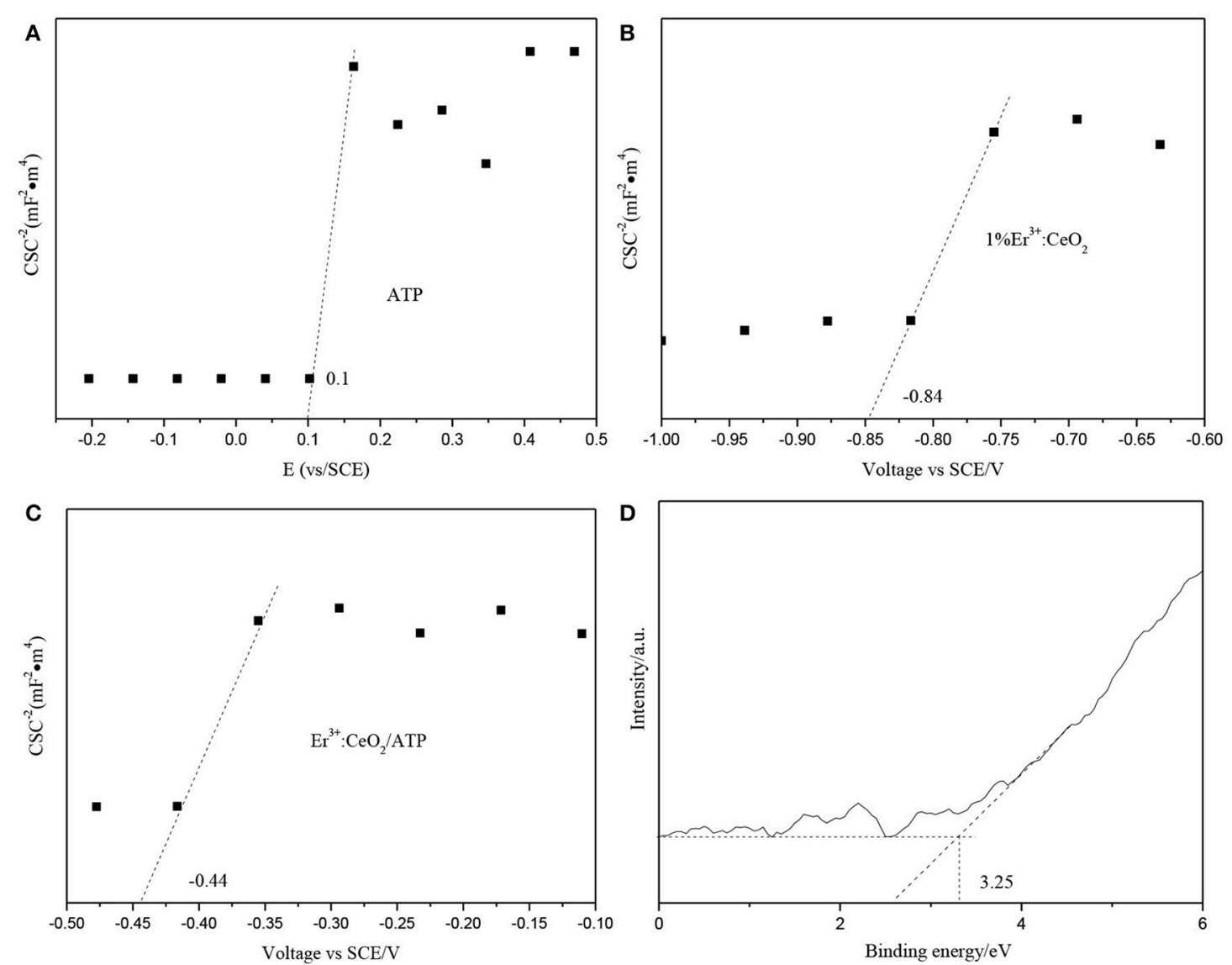

FIGURE 10 | Mott-schottky patterns of ATP (A), $1 \% \mathrm{Er}^{3+}: \mathrm{CeO}_{2}$ (B), $1 \% \mathrm{Er}^{3+}: \mathrm{CeO}_{2} / \mathrm{ATP}(4: 10)$ (C), and VB-XPS pattern of ATP (D).

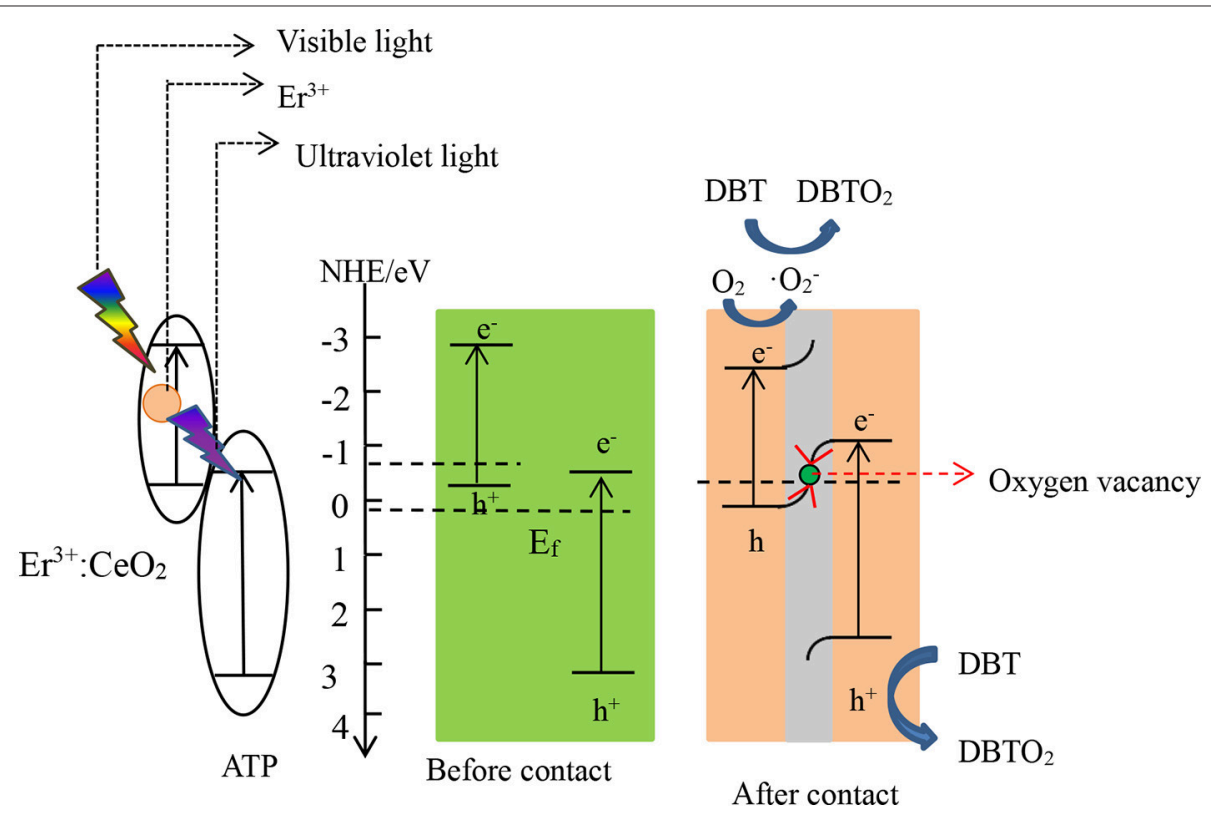

FIGURE 11 | Photocatalytic desulfurization mechanism of $\mathrm{Er}^{3+}: \mathrm{CeO}_{2} /$ ATP. 
be replaced by $\mathrm{Si}-\mathrm{O}-\mathrm{Ce}$ bond since the electronegativity of $\mathrm{Ce}$ is less than that of $\mathrm{Si}$.

\section{Photocatalytic Oxidation Desulfurization}

The photocatalytic oxidation desulfurization is performed using various catalysts. As shown in Figure 8, the desulfurization rate is $10.8,29.3$, and $34.3 \%$ corresponding to $\mathrm{ATP}, \mathrm{CeO}_{2}$ and $1 \% \mathrm{Er}^{3+}: \mathrm{CeO}_{2}$ samples. Meanwhile, the photocatalytic oxidation desulfurization rate of $1 \% \mathrm{Er}^{3+}: \mathrm{CeO}_{2} / \mathrm{ATP}$ (4:10) reaches $87 \%$. The $1 \% \mathrm{Er}^{3+}: \mathrm{CeO}_{2}$ and ATP may have synergy which accelerates the migration of photogenerated electrons and holes. Furthermore, a unique Z-type structure may form perseving the high redox potential, thus leads to the improved desulfurization performance.

Figure 9 shows the photocatalytic desulfurization performance with different mass ratios of $1 \% \mathrm{Er}^{3+}: \mathrm{CeO}_{2}$ and ATP. The desulfurization rate is enhanced gradually with the increase of the mass ratio. When the mass ratio is $4: 10$, the photocatalytic desulfurization rate of $1 \% \mathrm{Er}^{3+}: \mathrm{CeO}_{2} / \mathrm{ATP}$ reached $87 \%$ within $4 \mathrm{~h}$, which may be due to the fact that with the content of $1 \% \mathrm{Er}^{3+}: \mathrm{CeO}_{2}$ increased, the concentration of oxygen vacancy is increased favoring for the transmission of charges. When the mass ratio is more than $4: 10$, the photocatalytic desulfurization rate is decreased, since the excess $\mathrm{Er}^{3+}: \mathrm{CeO}_{2}$ nanoparticles may lead to aggregation restraining the exposure of surface active sites and destroying the balance of recombination of charges.

\section{Photocatalytic Desulfurization Mechanism}

The position of conduction band (CB), valence band (VB) and Fermi energy levels $\left(\mathrm{E}_{\mathrm{f}}\right)$ of $1 \% \mathrm{Er}^{3+}: \mathrm{CeO}_{2}$ and ATP were calculated, respectively. Figures 10A,B show the Mott-schottky patterns of ATP and $1 \% \mathrm{Er}^{3+}: \mathrm{CeO}_{2}$, where the flat band tential (identical $\mathrm{E}_{\mathrm{f}}$ ) of ATP and $1 \% \mathrm{Er}^{3+}: \mathrm{CeO}_{2}$ is determined to be 0.1 and $-0.84 \mathrm{eV}$, respectively. Figure 10C shows the Mottschottky pattern of $1 \% \mathrm{Er}^{3+}: \mathrm{CeO}_{2} / \mathrm{ATP}(4: 10)$ after contact, and the equilibrium $\mathrm{E}_{\mathrm{f}}$ level is shifted to $-0.44 \mathrm{eV}$ located between that of $\mathrm{Er}^{3+}: \mathrm{CeO}_{2}$ and ATP. Figure 10D shows the VB-XPS pattern of ATP, in which the VB value of ATP is determined to be $3.25 \mathrm{eV}$. In addition, the empirical formula of $\mathrm{VB}$ and $\mathrm{CB}$ is as follows (Obregón et al., 2016):

$$
\begin{array}{r}
\mathrm{E}_{\mathrm{VB}}=\mathrm{X}-E^{e}+\frac{1}{2} E_{g} \\
\mathrm{E}_{\mathrm{CB}}=E_{V B}-E_{g}
\end{array}
$$

where $\mathrm{E}_{\mathrm{VB}}$ and $\mathrm{E}_{\mathrm{CB}}$ represent the $\mathrm{VB}$ and $\mathrm{CB}$ edge potential, respectively, $\mathrm{X}$ represents the electronegativity, $\mathrm{E}^{\mathrm{e}}$ (about $4.5 \mathrm{eV}$ ) is the energy of free electrons on the hydrogen, and $E_{g}$ is the band gap of the semiconductor. According to the above formula, the $\mathrm{VB}$ value for $1 \% \mathrm{Er}^{3+}: \mathrm{CeO}_{2}$ is calculated to be $-0.42 \mathrm{eV}$. Since the $\mathrm{E}_{\mathrm{g}}$ of ATP and $1 \% \mathrm{Er}^{3+}: \mathrm{CeO}_{2}$ is 3.75 and $2.51 \mathrm{eV}$ by $\mathrm{UV}-\mathrm{Vis}$ analysis in Figure 5, the corresponding CB for ATP and $1 \% \mathrm{Er}^{3+}: \mathrm{CeO}_{2}$ is -0.5 and $-2.93 \mathrm{eV}$, respectively.

According to the above analysis, the photocatalytic desulfurization mechanism of $1 \% \mathrm{Er}^{3+}: \mathrm{CeO}_{2} / \mathrm{ATP}$ (4:10) is proposed as shown in Figure 11. After contact, free electrons may flow from $1 \% \mathrm{Er}^{3+}: \mathrm{CeO}_{2}$ to ATP due to the disparity of $\mathrm{E}_{\mathrm{f}}$ until they reach equilibrium, which forms an internal electric field, leading to the consumption and accumulation of free electrons (Huang et al., 2017). Simultaneously, the energy band edge of $\mathrm{Er}^{3+}: \mathrm{CeO}_{2}$ is bended upward whereas the energy band edge of ATP is bended downward. Under visible light irradiation, the $1 \% \mathrm{Er}^{3+}: \mathrm{CeO}_{2}$ is stimulated to produce photogenerated $\mathrm{e}^{-}$ and $\mathrm{h}^{+}$while $\mathrm{Er}^{3+}$ converts visible light to ultraviolet light. Subsequently, ATP is stimulated by the upconverted ultraviolet light to produce photogenerated $\mathrm{e}^{-}$and $\mathrm{h}^{+}$. Then the downward band bending of ATP allows $e^{-}$flow to the oxygen vacancy in $\mathrm{CeO}_{2}$ while the upward band bending of $1 \% \mathrm{Er}^{3+}: \mathrm{CeO}_{2}$ allows $\mathrm{h}^{+}$flow to the oxygen vacancy which acted as the recombination center for the $\mathrm{e}^{-}$and $\mathrm{h}^{+}$(Ding et al., 2016). Finally, the photogenerated $\mathrm{e}^{-}$in the $\mathrm{CB}$ of $1 \% \mathrm{Er}^{3+}: \mathrm{CeO}_{2}$ is preserved and reacts with $\mathrm{O}_{2}$ to produce $\cdot \mathrm{O}_{2}^{-}$. Then, $\cdot \mathrm{O}_{2}^{-}$and $\mathrm{h}^{+}$in the $\mathrm{VB}$ of ATP synergistically oxidize DBT to $\mathrm{DBTO}_{2}$ (Li et al., 2018). According to the above statement, the reaction equations are put forward as follows:

$$
\begin{array}{r}
1 \% \mathrm{Er}^{3+}: \mathrm{CeO}_{2} / \mathrm{ATP}+\mathrm{hv} \rightarrow e^{-}+h^{+} \\
\mathrm{e}^{-}+\mathrm{O}_{2} \rightarrow \cdot \mathrm{O}_{2}^{-} \\
\mathrm{O}_{2}^{-}+\mathrm{DBT} \rightarrow \mathrm{DBTO}_{2} \\
\mathrm{~h}^{+}+\mathrm{DBT} \rightarrow \mathrm{DBTO}_{2}
\end{array}
$$

\section{CONCLUSION}

In this work, $\mathrm{Er}^{3+}: \mathrm{CeO}_{2} / \mathrm{ATP}$ nanocomposites have been successfully prepared via a one-step precipitation method. Doping of Er not only alters the band gap of $\mathrm{CeO}_{2}$, but also converts visible light to ultraviolet light and reach the strongest when the doping fraction of $\mathrm{Er}$ is $1 \% . \mathrm{Er}^{3+}: \mathrm{CeO}_{2}$ and ATP form Z-type heterostructure intermediated by oxygen vacancy, which promotes the transfer of photogenerated electrons and holes and preserves the charges with higher oxidation-reduction ability. The photocatalytic desulfurization rate reaches the highest $87 \%$ when the mass radio of $\mathrm{Er}^{3+}: \mathrm{CeO}_{2}$ and ATP is 4:10. This novel photocatalyst integrated by natural clay and rare earth upconversion may pave a new way for design of eco-friendly materials and beyond.

\section{AUTHOR CONTRIBUTIONS}

FW drafted the manuscript, XL made analysis and revision, HZ synthesized the samples and conducted desulfurization experiment, SZ characterized the samples, CY provided the idea and proposed the mechanism.

\section{FUNDING}

This work was supported by the National Science Foundation of China (51674043, 51702026), Jiangsu Key Laboratory of Advanced Catalytic Materials and Technology (BM2012110) and Priority Academic Program Development of Jiangsu Higher Education Institutions (PAPD). 


\section{REFERENCES}

Agarwal, M., Dikshit, P. K., Bhasarkar, J. B., Borah, A. J., and Moholkar, V. S. (2016). Physical insight into ultrasound-assisted biodesulfurization using free and immobilized cells of Rhodococcus rhodochrous MTCC 3552. Chem. Eng. J. 295, 254-267. doi: 10.1016/j.cej.2016.03.042

Balaji, R., Kumar, S., Reddy, K. L., Sharma, V., Bhattacharyya, K., and Krishnan, V. (2017). Near-infrared driven photocatalytic performance of lanthanidedoped $\mathrm{NaYF}_{4} @ \mathrm{CdS}$ core-shell nanostructures with enhanced upconversion properties. J. Alloys Compd. 724, 481-491. doi: 10.1016/j.jallcom.2017. 07.050

Bhethanabotla, V. C., Russell, D. R., and Kuhn, J. N. (2016). Assessment of mechanisms for enhanced performance of $\mathrm{Yb} / \mathrm{Er} /$ titania photocatalysts for organic degradation: part 2. Role of rare earth elements in the titania phase. Appl. Catal. B Environ. 202, 156-164. doi: 10.1016/j.apcatb.2016. 09.008

Ding, J., Dai, Z., Qin, F., Zhao, H., Zhao, S., and Chen, R. (2016). Z-scheme $\mathrm{BiO}_{1-\mathrm{x}} \mathrm{Br} / \mathrm{Bi}_{2} \mathrm{O}_{2} \mathrm{CO}_{3}$ photocatalyst with rich oxygen vacancy as electron mediator for highly efficient degradation of antibiotics. Appl. Catal. B Environ. 205, 281-291. doi: 10.1016/j.apcatb.2016.12.018

Feng, W., Han, C., and Li, F. (2013). Upconversion-nanophosphorbased functional nanocomposites. Adv. Mater. 25, 5287-5303. doi: 10.1002/adma.201301946

Han, G., Wang, M., Li, D., Bai, J., and Diao, G. (2017). Novel upconversion Er, $\mathrm{Yb}-\mathrm{CeO}_{2}$ hollow spheres as scattering layer materials for efficient dye-sensitized solar cells. Solar Energy Mater. Solar Cells 160, 54-59. doi: 10.1016/j.solmat.2016.10.021

Huang, Z.-F., Song, J., Wang X., Pan, L., Li, K., Zhang, X., et al. (2017). Switching charge transfer of $\mathrm{C}_{3} \mathrm{~N}_{4} / \mathrm{W}_{18} \mathrm{O}_{49}$ from type-II to Z-scheme by interfacial band bending for highly efficient photocatalytic hydrogen evolution. Nano Energy 40 , 308-316. doi: 10.1016/j.nanoen.2017.08.032

Khodadadi Dizaji, A., Mortaheb, H. R., and Mokhtarani, B. (2018). Complete oxidative desulfurization using graphene oxide-based phosphomolybdic acid catalyst: process optimization by two phase mass balance approach. Chem. Eng. J. 335, 362-372. doi: 10.1016/j.cej.2017.10.129

Kumar, S., and Kumar, A. (2017). Enhanced photocatalytic activity of rGO$\mathrm{CeO}_{2}$ nanocomposites driven by sunlight. Mater. Sci. Eng. B 223, 98-108. doi: 10.1016/j.mseb.2017.06.006

Li, X., Li, F., Lu, X., Zuo, S., Li, Z., Yao, C., et al. (2018). Microwave hydrothermal synthesis of $\mathrm{BiP}_{1-\mathrm{x}} \mathrm{V}_{\mathrm{x}} \mathrm{O}_{4}$ /attapulgite nanocomposite with efficient photocatalytic performance for deep desulfurization. Powder Technol. 327, 467-475. doi: 10.1016/j.powtec.2018.01.005

Li, X., Ni, C., Yao, C., and Chen, Z. (2012). Development of attapulgite/ $\mathrm{Ce}_{1-\mathrm{x}} \mathrm{Zr}_{\mathrm{x}} \mathrm{O}_{2}$ nanocomposite as catalyst for the degradation of methylene blue. Appl. Catal. B Environ. 117-118, 118-124. doi: 10.1016/j.apcatb.2012.01.008

Li, X., Zhang, Z., Yao, C., Lu, X., Zhao, X., and Ni, C. (2016). Attapulgite-CeO $2 / \mathrm{MoS} 2$ ternary nanocomposite for photocatalytic oxidative desulfurization. Appl. Surf. Sci. 364, 589-596. doi: 10.1016/j.apsusc.2015.12.196

Li, X., Zhu, W., Lu, X., Zuo, S., Yao, C., and Ni, C. (2017). Integrated nanostructures of $\mathrm{CeO}_{2}$ /attapulgite/g- $\mathrm{C}_{3} \mathrm{~N}_{4}$ as efficient catalyst for photocatalytic desulfurization: mechanism, kinetics and influencing factors. Chem. Eng. J. 326, 87-98. doi: 10.1016/j.cej.2017.05.131

Liu, R., Zhang, J., Xu, Z., Zhao, D., and Sun, S. (2017). Visible light photocatalytic oxidative desulfurization using Ti-MCM-41-loaded iron phthalocyanine combined with ionic liquid extraction. J. Mater. Sci. 53, 4927-4938. doi: 10.1007/s10853-017-1954-0

Ma, S., Li, X., Lu, X., Zuo, S., Li, Z., and Yao, C. (2018). Carbon quantum dots/attapulgite nanocomposites with enhanced photocatalytic performance for desulfurization. J. Mater. Sci. Mater. Electron. 29, 2709-2715. doi: 10.1007/s10854-017-8197-3

Mamontov, G. V., Grabchenko, M. V., Sobolev, V. I., Zaikovskii, V. I., and Vodyankina, O. V. (2016). Ethanol dehydrogenation over $\mathrm{Ag}-\mathrm{CeO}_{2} / \mathrm{SiO}_{2}$ catalyst: role of $\mathrm{Ag}-\mathrm{CeO}_{2}$ interface. Appl. Catal. A Gen. 528, 161-167. doi: 10.1016/j.apcata.2016.10.005

Obregón, S., Zhang, Y., and Colón, G. (2016). Cascade charge separation mechanism by ternary heterostructured $\mathrm{BiPO}_{4} / \mathrm{TiO}_{2} / \mathrm{g}-\mathrm{C}_{3} \mathrm{~N}_{4}$ photocatalyst. Appl. Catal. B Environ. 184, 96-103. doi: 10.1016/j.apcatb.2015.11.027
Peng, R., Li, S., Sun, X., Ren, Q., Chen, L., Fu, M., et al. (2017). Size effect of Pt nanoparticles on the catalytic oxidation of toluene over $\mathrm{Pt} / \mathrm{CeO}_{2}$ catalysts. Appl. Catal. B Environ. 220, 462-470. doi: 10.1016/j.apcatb.2017.07.048

Pickering, J. W., Bhethanabotla, V. R., and Kuhn, J. N. (2017). Assessment of mechanisms for enhanced performance of $\mathrm{TiO}_{2} / \mathrm{YAG}: \mathrm{Yb}^{+3}, \mathrm{Er}^{+3}$ composite photocatalysts for organic degradation. Appl. Catal. B Environ. 202, 147-155. doi: 10.1016/j.apcatb.2016.09.007

Raj, J. J., Magaret, S., Pranesh, M., Lethesh, K. C., Devi, W. C., and Mutalib, M. I. A. (2017). Extractive desulfurization of model fuel oil using ester functionalized imidazolium ionic liquids. Sep. Purif. Technol. 196, 115-123. doi: 10.1016/j.seppur.2017.08.050

Ramasamy, P., Chandra, P., Rhee, S. W., and Kim, J. (2013). Enhanced upconversion luminescence in NaGdF4:Yb,Er nanocrystals by $\mathrm{Fe}^{3+}$ doping and their application in bioimaging. Nanoscale 5, 8711-8717. doi: $10.1039 / \mathrm{c} 3 \mathrm{nr} 01608 \mathrm{k}$

Šutka, A., Vanags, M., Joost, U., Šmits, K., RuŽa, J., Ločs, J., et al. (2018). Aqueous synthesis of Z-scheme photocatalyst powders and thinfilm photoanodes from earth abundant elements. J. Environ. Chem. Eng.6, 2606-2615. doi: 10.1016/j.jece.2018.04.003

Wang, L., Wang, W. Y., Mominou, N., Liu, L. X., and Li, S. Z. (2016). Ultradeep desulfurization of gasoline through aqueous phase in-situ hydrogenation and photocatalytic oxidation. Appl. Catal. B Environ. 193, 180-188. doi: 10.1016/j.apcatb.2016.04.032

Wu, H., Yang, Z., Liao, J., Lai, S., Qiu, J., Song, Z., et al. (2014). Upconversion luminescence properties of three-dimensional ordered macroporous $\mathrm{CeO}_{2}: \mathrm{Er}^{3+}, \mathrm{Yb}^{3+}$. J. Alloys Compd. 586, 485-487. doi: $10.1016 /$ j.jallcom.2013.10.124

Yang, Y., Lv, G., Li, J., Guo, W., and Zhang, Y. (2018). Synthesis of ceria nanorods as adsorbent for the adsorption desulfurization of gasoline fuel. J. Alloys Compd. 747, 189-196. doi: 10.1016/j.jallcom.2018.03.026

Zeng, X., Xiao, X., Li, Y., Chen, J., and Wang, H. (2017). Deep desulfurization of liquid fuels with molecular oxygen through graphene photocatalytic oxidation. Appl. Catal. B Environ. 209, 98-109. doi: 10.1016/j.apcatb.2017.02.077

Zhang, G., Ren, J., Liu, B., Tian, M., Zhou, H., and Zhao, J. (2018). In situ hydrothermal preparation and photocatalytic desulfurization performance of metallophthalocyanine sensitized $\mathrm{SnO}_{2}$. Inorg. Chim. Acta 471, 782-787. doi: 10.1016/j.ica.2017.12.025

Zhang, G., Wang, H., Guo, S., Wang, J., and Liu, J. (2016b). Synthesis of $\mathrm{Cu} / \mathrm{TiO}_{2}$ /organo-attapulgite fiber nanocomposite and its photocatalytic activity for degradation of acetone in air. Appl. Surf. Sci. 362, 257-264. doi: 10.1016/j.apsusc.2015.11.218

Zhang, J., Chen, A., Wang, L., Li, X. A., and Huang, W. (2016a). Striving toward visible light photocatalytic water splitting based on natural silicate clay mineral: the interface modification of attapulgite at the atomic-molecular level. ACS Sust. Chem. Eng. 4, 4601-4607. doi: 10.1021/acssuschemeng.6b00716

Zhang, J., He, R., and Liu, X. (2013). Efficient visible light driven photocatalytic hydrogen production from water using attapulgite clay sensitized by CdS nanoparticles. Nanotechnology 24:505401. doi: 10.1088/0957-4484/24/50/505401

Zhao, H., Qiu, F., Yan, J., Wang, J., Li, X., and Yang, D. (2016). Preparation of economical and environmentally friendly graphene/palygorskite/ $\mathrm{TiO}_{2}$ composites and its application for the removal of methylene blue. Appl. Clay Sci. 121-122, 137-145. doi: 10.1016/j.clay.2015.12.009

Zhuo, S., Shao, M., and Lee, S. T. (2012). Upconversion and downconversion fluorescent graphene quantum dots: ultrasonic preparation and photocatalysis. ACS Nano 6, 1059-1064. doi: 10.1021/nn2040395

Conflict of Interest Statement: The authors declare that the research was conducted in the absence of any commercial or financial relationships that could be construed as a potential conflict of interest.

Copyright (๑) $2018 \mathrm{Wu}$, Li, Zhang, Zuo and Yao. This is an open-access article distributed under the terms of the Creative Commons Attribution License (CC BY). The use, distribution or reproduction in other forums is permitted, provided the original author(s) and the copyright owner(s) are credited and that the original publication in this journal is cited, in accordance with accepted academic practice. No use, distribution or reproduction is permitted which does not comply with these terms. 